
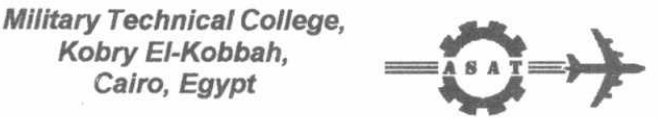

$9^{\text {th }}$ International Conference

On Aerospace Sciences \&

Aviation Technology

\title{
A STUDY OF SOME SURFACE CHARACTERISTICS WHEN BURNISHING WITH A NEW TOOL
}

\author{
EI-AXIR*M. H. and EL-KHABEERY** M. M
}

\begin{abstract}
Burnishing is used increasingly as a finishing operation which gives additional advantages such as increased hardness, fatigue strength, wear resistance. It is well known that burnished surface characteristic can significantly affect the resistance of components to failure when subjected to high cycle fatigue loads. The fatigue crack, in general, nucleates at the surface of the part, and then propagates into the bulk. Consequently, it is the state of the surface characteristic, where the crack nucleates, that is of paramount importance.
\end{abstract}

Experimental work based on Response Surface Methodology was carried out on a lathe to establish the effect of four roller burnishing tool parameters; namely, burnishing speed, depth of penetration, burnishing time and the initial hardness of five different materials on the surface hardness, the out-of-roundness and the change in workpiece diameter. The latter plays an important role to determine the required tolerance and consequently the type of fit.

It was found that all input parameters have a controlling effect, with different percentage, on the three output responses. The results showed that depth of penetration and burnishing time are the most important two parameters controlling the values of both out-of-roundness and change in workpiece diameter. Also, an increase in burnishing speed leads to a considerable reduction in the microhardness index. Out-of-roundness increases with a decreasing in the initial hardness of workpiece material

\section{KEY WORDS}

Burnishing Process, Microhardness, out-of-roundness, and Surface Roundness

*Assistant Professor, "*Associate Professor, Department of Production Engineering and Mechanical Design, Faculty of Engineering, Shebin El-kom, Egypt.

E-mail: ealaxir@yahoo.com 


\section{INTRODUCTION}

During recent years, considerable attention is being paid to the post-machining metal finishing operations such as burnishing which improves the surface characteristics by plastic deformation of the surface layers[1,2]. Burnishing is essential a cold-forming process, in which the metal near a machined surface is displaced from protrusion to fill the depressions. Beside producing a good surface finish, the burnishing process has additional advantages over other machining processes, such as securing increased hardness, corrosion resistance and fatigue life as a result of the producing compressive residual stress. Residual stresses are probably the most important aspect in assessing integrity because of their direct influence on performance in service. Thus control of the burnishing process (burnishing conditions) in such a way as to produce compressive residual stresses in the surface region could lead to considerable improvement in component life.

A comprehensive classification of burnishing tools and their application has been given by Shneider [3]. A literature survey shows that work on the burnishing process has been conducted by many researchers and the process also improves the properties of the parts, e.g. increased hardness [4-7], surface quality [2,4,8,9], increased maximum residual stress in compression $[4,10]$, and higher wear resistance $[11,12]$ The parameters affecting the surface finish are: burnishing force, feed rate, ball material, number of passes, workpiece material, and lubrication [2].

This paper examines the use of a new roller burnishing tool to give a good surface characteristic such as, surface microhardness, surface roundness and the change in workpiece diameter that play an important role on the required tolerance and fit especially during assembly parts. To explore the optimum combination of burnishing parameters in an efficient and quantitative manner, the experiments were designed based on the response surface methodology (RSM) with central composite rotatable design. The effect of four parameters; three burnishing parameters, namely; burnishing speed, feed, and burnishing; the fourth independent parameters chosen was hardness of materials.

\section{EXPERIMENTAL WORK}

In this study, 2014 Aluminum alloy, brass and three different carbon steel materials: namely, A387 Grade II, A285, and A 455 Type I, (according to ASTM specification) were used as workpiece materials. These materials were selected because of their importance in industry and their susceptibility to degradation when burnished, through surface and subsurface damage. The chemical analysis, in weight percent, of these materials is shown in Table 1 . Specimens were turned and burnished on a center lathe Model DIZ 450x 1600, WMW, Germany. 
Table 1: Chemical Composition of Workpiece Materials in weight percent

\begin{tabular}{|c|c|c|c|c|c|c|c|c|c|c|c|c|c|}
\hline Material & \multicolumn{10}{|c|}{ Chemical composition } \\
\hline $\begin{array}{c}\text { Aluminum } \\
2014\end{array}$ & $\mathrm{Fe}$ & $\mathrm{C}$ & $\mathrm{Cu}$ & $\mathrm{Mn}$ & $\mathrm{Mg}$ & $\mathrm{Cr}$ & $\mathrm{Zn}$ & $\mathrm{Ti}$ & $\mathrm{Mo}$ & $\mathrm{S}$ & $\mathrm{P}$ & $\mathrm{Pb}$ & $\mathrm{Si}$ \\
$\mathbf{0 . 7}$ & & $3.9-5$ & $0.4-1.2$ & $0.2-0.8$ & 0.1 & 0.25 & 0.15 & & & & & $0.5-1.2$ \\
\hline Brass & 0.043 & & 57.68 & & & & 40.29 & & & & & 1.99 & \\
\hline $\begin{array}{c}\text { A335-grade11 } \\
\text { A285-gradeC } \\
\text { A455-type I }\end{array}$ & & $\begin{array}{c}0.17 \\
0.28\end{array}$ & & $\begin{array}{c}0.4-0.65 \\
0.90\end{array}$ & & $1-1.5$ & & & $0.45-0.65$ & 0.04 & 0.035 & & $0.5-0.8$ \\
$0.85-12$ & & & & & & & 0.045 & 0.035 & & \\
0.05 & 0.4 & & 0.10 \\
\hline
\end{tabular}

The five different materials were received in the form of seamless tube that was machined into ring-shaped workpiece having dimensions shown in Fig.1. The workpiece were prepared with two parts $A$ and $B$. Part (A) was left without burnishing for comparison. In the burnishing tests, the ring-shaped specimens were held by means of screw and nut in a specially made mandrel, the direction of the burnishing roller pressure being perpendicular to the axis of rotation of workpiece. Figure 2 shows a ring-shaped specimen attached to the mandrel. The surface hardness of each specimen was measured along the length and around the periphery. A microhardness tester (SHIMSADZU MICRO HARDNESS TERSTER TYPE-M) was used in these measured. Burnishing process usually reduces the workpiece dimensions in the direction of main deformation. The change in the diameter was measured at different places for each test using a horizontal Microscope (CARLZEISS MODEL 2063)

It is practically impossible to produce the geometry of engineering products perfectly in agreement with the ideal dimensions of the component. A roundness error is considered as one of the important geometrical error for cylindrical components because it has negative effects on accuracy and other important factors such as the filling machine elements, and wear in rotating elements. The roundness is obtained as the difference between the maximum and minimum radii of the measured profile. Roundness variation was measured using a Circularity error device Model (RANDCOM IC AFFERENT).

The hardness of both the pre-machined and burnished surfaces were measured using Vecker's hardness tester (SHIMSADZU MICRO HARDNESS TESTER TUPEM). A pyramid diamond indentor with $136^{\circ}$ apex and indentation load of $1 \mathrm{kgf}$ was used. The average hardness of the pre-machined surface for the five materials used in this work were taken.

A new specially designed burnishing tool is shown in Fig. 3 which consists of two steel parts. The first part is the base that can be held on the tool post of the lathe whereas the other part is made to hold the roller freely. A roller bearing having an outside diameter of $22 \mathrm{~mm}$ and a width of $6 \mathrm{~mm}$ was fitted to the tool. The input factors 
under investigation in the experiments were; burnishing speed, depth of penetration, and burnishing time and initial hardness of the workpiece materials.

In this investigation, experiments were designed on the basis of the experiments design technique. Detail description of this technique is presented elsewhere [14] According to a central composed-second-order rotatable design with four independent variables, the total number, $\mathrm{N}$, of experiments is determined to be 31 The cutting conditions and their coded are summarized in Table 2.

Table 2: Summary of Burnishing Conditions

\begin{tabular}{|c|c|c|c|c|c|c|}
\hline \multirow[t]{2}{*}{ Parameters } & \multirow[t]{2}{*}{ Symbol } & \multicolumn{5}{|c|}{ Levels in code form } \\
\hline & & -2 & -1 & 0 & 1 & 2 \\
\hline Burnishing speed, $\quad(\mathrm{m} / \mathrm{s})$ & $x_{1}$ & 1.04 & 1.37 & 1.693 & 2.006 & 2.3411 \\
\hline Depth of penetration, $(\mathrm{mm})$ & $x_{2}$ & 0.4 & 0.6 & 0.8 & 1 & 1.2 \\
\hline Burnishing time, (sec) & $x_{3}$ & 10 & 20 & 30 & 40 & 50 \\
\hline Material hardness, & $x_{4}$ & 50 & 60 & 70 & 80 & 90 \\
\hline $\begin{array}{l}\text { Roller diameter } \\
\text { Burnishing condition }\end{array}$ & & & & $\begin{array}{r}22 \mathrm{~m} \\
\text { Lubric }\end{array}$ & & \\
\hline
\end{tabular}

\section{PRESENTATION OF RESULTS}

Table 2 shows the results of the thirty-one experiments carried out in this research from which the response microhardness; Hv, as functions of the four parameters used in this work is deduced after deletion of the insignificant coefficient using Student's t-test. The final equation of the percentage of microhardness increase is as the following

$H_{v}=44.98-11.05 X_{1}+6.129 X_{2}+9.466 X_{3}+8.909 X_{33}^{2}-11.69 X_{2} X_{3}-7.813 X_{2} X_{4}$

To study and discuss the effect of the input parameters on the percentage of surface microhardness increase, the above equation is used and the results are presented in Figs. 6-11.

It is to be expected that the burnishing process causes a reduction in dimension related to surface roughness because the burnishing tool flats topographical peaks. The relationship between the input parameters and the change in workpiece diameter is derived as in the following equation:

$$
\begin{aligned}
& \Delta D=33.55-11.95 X_{1}+8.965 X_{2}+18.31 X_{3}-7.71 X_{4}+6.88 X_{1}^{2}+5.88 X_{3}^{2}+10.125 X_{4}^{2} \\
& \ldots \ldots+7.813 X_{2} X_{3}
\end{aligned}
$$


Table 2 : Experimental conditions and results

\begin{tabular}{|c|c|c|c|c|c|c|c|c|c|c|c|}
\hline NO & $\begin{array}{r}\text { But } \\
s \\
\text { code } \\
X_{1}\end{array}$ & $\begin{array}{l}\text { nishing } \\
\text { peed } \\
\text { actual } \\
v\end{array}$ & $\begin{array}{l}\text { Burr } \\
\text { Dep } \\
\text { Cod } \\
X_{2}\end{array}$ & $\begin{array}{l}\text { shing } \\
\text { of pent } \\
\text { actual } \\
\text { d }\end{array}$ & $\begin{array}{r}\text { Bu } \\
\operatorname{cod} \\
X\end{array}$ & $\begin{array}{l}\text { shing } \\
\text { ne } \\
\text { actual } \\
t\end{array}$ & $\begin{array}{r}\mathrm{Me} \\
\mathrm{Ha} \\
\text { code } \\
\mathrm{X}_{4}\end{array}$ & $\begin{array}{l}\text { arial } \\
\text { ness } \\
\text { actual } \\
\text { H }\end{array}$ & $\begin{array}{c}\text { Hv-Index } \\
\%\end{array}$ & $\begin{array}{l}\Delta D \\
\mu m\end{array}$ & $\begin{array}{l}\text { Out-of- } \\
\text { roundness } \\
\mu \mathrm{m}\end{array}$ \\
\hline 1 & -1 & $(1.37)$ & -1 & $(0.6)$ & -1 & (20) & -1 & (60) & 47 & 55 & 8 \\
\hline 2 & 1 & $(2.006)$ & -1 & $(0.6)$ & -1 & (20) & -1 & (60) & 22 & 35 & $2 \mathrm{C}$ \\
\hline 3 & -1 & $(1.37)$ & 1 & (1) & -1 & (20) & -1 & (60) & 85 & 59 & 5 \\
\hline 4 & 1 & $(2.006)$ & 1 & (1) & -1 & (20) & -1 & (60) & 58 & 48 & 17 \\
\hline 5 & -1 & $(1.37)$ & -1 & $(0.6)$ & 1 & (40) & -1 & (60) & 62 & 76 & 3 \\
\hline 8 & 1 & $(2.006)$ & -1 & $(0.6)$ & 1 & (40) & -1 & (60) & 25 & 52 & 9 \\
\hline 7 & -1 & $(1.37)$ & -1 & $(0.6)$ & 1 & (40) & -1 & (60) & 69 & 134 & 4 \\
\hline 8 & 1 & $(2.006)$ & -1 & $(0.6)$ & 1 & (40) & -1 & $(60)$ & 34 & 92 & 8 \\
\hline 8 & -1 & $(1.37)$ & 1 & (1) & -1 & (20) & 1 & (80) & 37 & 50 & 5 \\
\hline 10 & 1 & $(2.006)$ & 1 & (1) & -1 & (20) & 1 & (80) & 20 & 17 & 10 \\
\hline 11 & -1 & $(1.37)$ & -1 & $(0.6)$ & -1 & (20) & 1 & (80) & 46 & 44 & 3 \\
\hline 12 & 1 & $(2.006)$ & -1 & $(0.6)$ & -1 & (20) & 1 & (80) & 58 & 41 & 6 \\
\hline 13 & -1 & $(1.37)$ & -1 & $(0.6)$ & 1 & (40) & 1 & (80) & 83 & 66 & 2 \\
\hline 14 & 1 & $(2.006)$ & -1 & $(0.6)$ & 1 & (40) & 1 & (80) & 63 & 40 & 7 \\
\hline 15 & -1 & $(1.37)^{\prime}$ & 1 & (1) & 1 & (40) & 1 & (80) & 50 & 108 & 3 \\
\hline 16 & 1 & $(2.006)$ & 1 & (1) & 1 & (40) & 1 & (8c) & 14 & 60 & 6 \\
\hline 17 & -2 & $(1.04)$ & 0 & $(0.8)$ & 0 & (30) & 0 & (70) & 55 & 70 & 10 \\
\hline 18 & 2 & (2.341) & 0 & $(0.8)$ & 0 & (30) & 0 & (70) & 15 & 30 & 20 \\
\hline 19 & 0 & (1.693) & -2 & $(0.4)$ & 0 & (30) & 0 & (70) & 22 & 10 & 7 \\
\hline 20 & 0 & (1.693) & 2 & (1.2) & 0 & (30) & 0 & (70) & 68 & 20 & 4 \\
\hline 21 & 0 & (1.693) & 0 & $(0.8)$ & -2 & (10) & 0 & (70) & 30 & 6 & 7 \\
\hline 22 & 0 & (1.693) & 0 & $(0.8)$ & 2 & (50) & 0 & (70) & 130 & 86 & 4 \\
\hline 23 & 0 & (1.693) & 0 & $(0.8)$ & 0 & (30) & -2 & (50) & 42 & 78 & 10 \\
\hline 24 & 0 & (1.693) & 0 & $(0.8)$ & 0 & (30) & 2 & (90) & 10 & 48 & 4 \\
\hline 25 & 0 & (1.693) & 0 & $(0.8)$ & 0 & (30) & 0 & (70) & 58 & 45 & 2 \\
\hline 26 & 0 & (1.693) & 0 & $(0.8)$ & 0 & (30) & 0 & (70) & 60 & 35 & 7 \\
\hline 27 & 0 & (1.693) & 0 & $(0.8)$ & 0 & (30) & 0 & (70) & 58 & 30 & 8 \\
\hline 28 & 0 & (1.693) & 0 & $(0.8)$ & 0 & (30) & 0 & (70) & 25 & 20 & 8 \\
\hline 29 & 0 & (1.693) & 0 & $(0.8)$ & 0 & (30) & 0 & (70) & 37 & 50 & 7 \\
\hline 30 & 0 & (1.693) & 0 & $(0.8)$ & 0 & (30) & 0 & (70) & 42 & 22 & 5 \\
\hline 31 & 0 & $(1.693)$ & 0 & $(0.8)$ & 0 & (30) & 0 & (70) & 35 & 33 & 7 \\
\hline
\end{tabular}

It should be noted from the final equation that there is some coefficients omitted. These coefficients are non-significant according to the Student's t-test that determines the significant and non-significant parameters. Also, the final models tested by variance analysis (F-test) indicating that the adequacy on the models is established. The effect of used parameters on the change in workpiece diameter are illustrated in Figs. 6-11.

Out-of-roundness play an important role on the efficiency of any round mechanical part that rotates during work. In any engineering factory, it will be seen that many machines, such as, lathes are used to make round component, a shaft as an example, may appear to be round to the eyes. It may even have a constant diameter when measured with any instrument but when examine the shape on a greatly enlarged scale it could be seen as shown in Fig.4. It is clear that the lobes will carry most of the load of the shaft when it runs in a plan bearing. This leads to less efficiently than the designer wanted. 
Out-of-roundness of any mechanical part could be due to deflection of the workpiece as a result of the forces generated during cutting. Also, out-of-roundness may be produced as a result of tool wear or incorrect in the position. The range of out-ofroundness error of any mechanical part depends strongly on cutting parameters, namely, cutting speed feed rate, depth of cut and tool geometry that control the behavior of both tool forces and tool wear. One of the main objectives of this work is to study the effects of burnishing process on the out-of-roundness. Figure 5 shows, for example, a comparison between the out-of-roundness error before (turning) and after burnishing process for one test.

It is interesting to report that the out-of-roundness considerably reduces as a result of burnishing at all levels of parameters used in this work. Also, it is interesting to mention that about $2 \mu \mathrm{m}$. out-of-roundness error can be obtained by burrisishing process. The result could be considered as a new advantage of burnishing process.

The final equation of the out-of-roundness error is:

$O R=5.57+2.67 X_{1}-1.001 X_{2}-1.334 X_{3}-1.585 X_{4}+2.1053 X_{1}^{2}+1.125 X_{2} X_{3}$

To study and discuss the effect of the input parameters on the out-of-roundness the above equation is used and the results are presented in Figs. 6-11.

\section{RESULTS DISCUSSION}

\section{4-1. Burnishing Speed}

The effect of burnishing speed on the percentage of microhardness increase, change in workpiece diameter (reduction in diameter dimension) and the variation of out-ofroundness can be assessed from Figs. 6-8. The results reveal that an increase in burnishing speed leads, in general, to a decrease in the percentage of microhardness increase of surface layers. This is partly due to the fact that the deforming action of the roller is smaller at high speed and partly due to the chaiter that usually induces at high speed.

It can generally be seen for the various depth of penetration, time, initial hardness used in this work that reduction in workpiece diameter decreases with an increase in burnishing speed, reaching a minimum value at a burnishing speed of $2.006 \mathrm{~m} / \mathrm{s}$. A further increase in speed than $2.006 \mathrm{~m} / \mathrm{s}$ causes an increase in reduction in workpiece diameter. It is believed that the increase in the diameter change at low speed is possible due to the high deforming action of the rollers of burnishing tool.

Also, from the same figures, it can be seen that as the burnishing speed increase (from 1.04 to $1.6993 \mathrm{~m} / \mathrm{s}$ ) the out-of-roundness first decreases to a minimum value. With a further increase in burnishing speed, out-of-roundness begins to increase gradually. A combination of high speeds with high value of any one of the other 
parameters used in this work increases the out-of-roundness because of chatters which usually occurs at this condition

\section{4-2. Depth of Penetration}

Depth of penetration is one of the very important burnishing parameters that affect the results of this four roller-burnishing tool. It can be seen form Fig.6, that for a given speed, an increase in depth of penetration causes an increase in both microhardness increase percentage and reduction in diameter dimension of the burnished surface. The increase in both the percentage of microhardness increase and the reduction in diameter dimension when employing high depth of penetration can be attributed to the increase of the roller pressure on the workpiece surface resulting in compressing the most aspirates and increase the metal flow which leads to the filling of more voids that were exited in subsurface layer due to machining operation (turning, or as a metal defect). The out-of-roundness of the burnished surface, as shown in the above figures, decreases as the depth of penetration increased as a result of the regularity of the metal flow on the burnished surface.

Figure 9 presents the relationship between the three output responses measured in this work and depth of penetration for different burnishing times. There is two interactions in this figure, the first is between both depth of penetration and burnishing time and the microhardness increase percentage. A combination of low depth of penetration with high time leads to a substantial improvement in the percentage of microhardness increase. A combination of high depth of penetration with high burnishing time deteriorates the percentage of microhardness increase. It is believed that this occurs because of the over hardening and consequently flaking of the surface layers.

The second interaction is between the same two parameters and the reduction in diameter dimension. The magnitude of penetration that gives low change in diameter depends on the value of time during burnishing process. Also, it can be realized that the combination between high roller penetration and high burnishing time results in an increase in diameter change. This attributed to repetition of burnishing process for the same work under the specified penetration

Also, the results of this figure shows that at high depth of penetration, increases in burnishing time result in an increase in the out-of-roundness. It is believed that combination of high depth of penetration with high burnishing time leads to over hardening and then flaking. The best results were obtained at the combination of low burnishing time with high depth of penetration as shown in Fig. 9.

\section{4-3. Burnishing Time}

The effect of burnishing time on the percentage of the studied three different responses is shown in Figs. 7, 9 and 11). The results of these figures show that the burnishing time is one of the most controlling parameters influence on the change in the results of the three responses. These figures, generally reveal that as the burnishing time increases the percentage of microhardness increase first reaches a 
maximum value. This is because the repeating of the burnishing process on the same workpiece surface at high burnishing time that leads to an increase in the structure homogeneity which results in an increase in the surface responses. With a further increase in burnishing time, the percentage of microhardness increase begins to decrease gradually. This is because, increasing the burnishing time more than a certain time deteriorates the results because of the over hardening and consequently flaking of the surface layers as a result of more repeating roller burnishing tool on the same workpiece surface.

The highest variation in workpiece diameter can be obtained at high burnishing time. Magnitude of burnishing time that gives low change in diameter depends on the depth of penetration.

It is clear that for a given burnishing speed and/or initial hardness of the workpiece material an increase in burnishing time leads to a decrease in the out-of-roundness. It is interesting to discuss the reasons why the out-of-roundness is decreased. It is thought that the repeated contacts the tool (roller) and workpiece, the elastic contact is achieved for most the contact area and the plastic deformation occurs only at the minute area around the center of contact of the burnishing so that plastic deformation does not extend over the surroundings.

\section{4-4. Initial Hardness of Material}

The influence of the Initial hardness of workpiece material on the percentage of the surface microhardness increase, the reduction in diameter dimension and the out-ofroundness at different burnishing speed, depth of penetration and burnishing time is shown in Figs. 8, 10, and 11. In general, at a given burnishing speed or burnishing time, the percentage of microhardness increase of the burnished surface increases as the initial hardness increased from 50 to $70 \mathrm{HB}$. With a further increase in initial hardness, the percentage of microhardness increase begins to decrease gradually.

Figure 10 shows that there is an interaction between both Initial hardness of material and depth of penetration and the percentage of microhardness increase. At low initial hardness of workpiece material, an increase in the burnishing depth penetration leads to an increase in the percentage of microhardness increase. However, at high initial hardness an increase in burnishing depth of penetration decreases the percentage of microhardness increase

It can be seen from these figures that the change in diameter first decrease with an increase in initial hardness to a minimum as a result of the increasing of the ability of the workpiece surface to resist the roller burnishing tool pressure. With a further increase in the initial hardness of workpiece material over $70 \mathrm{HB}$, the change in workpiece diameter increases as a result of over hardening.

The general trend of the results of out-of-roundness is that lowering the initial hardness of material leads to a considerable increase in the out-of-roundness. This may occur as a result of the irregularity of the metal flow. Therefore, it is better to conduct burnishing process on middle or hard metal to obtain a significant decrease in the out-of-roundness. 


\section{CONCLUSIONS}

From the analysis of the experimental data and the identified predictive models, the following conclusions can be drawn

(1) The output responses of the burnished surface are mainly influenced by the four parameters used. The depth of penetration and burnishing time play a major role and their effects can be considered as the most important input parameters

(2) An increase in burnishing speed leads to a decrease in both the percentage of microhardness increase and change in workpiece diameter whereas the increase in burnishing speed more than $1.5 \mathrm{~m} / \mathrm{sec}$ result in a considerable increase in out-of-roundness.

(3) An increase in depth of penetration leads to a considerable increase in both surface microhardness and change in workpiece diameter whereas it causes a decrease in the out-of-roundness. Depth of penetration interacts with both burnishing time and initial hardness of workpiece material. The best results for surface microhardness obtained at both low depth of penetration with high burnishing time and/or high depth of penetration with low initial hardness of material.

(4) The best results for surface out-of-roundness obtained at high depth of penetration with low burnishing time.

(5) The principle factors which affects the results of the effects of both depth of penetration and burnishing time on all surface responses are the workpiece over hardening and then flaking that generally occurs using a combination of high burnishing time with high depth of penetration and the great deforming action of the tool and the increasing of structural homogeneity of the surface layers that occurs using high depth of penetration with low burnishing time

(6) The initial hardness of workpiece material is one of the most important parameters controlling the effects of the other parameters on each response. There is many interactions between initial hardness of material and other parameters used in this work showing that the effect of any input parameters depends on mainly the initial hardness of workpiece material.

\section{REFERENCES}

[1] Kukielka, L. " Designating the Field Areas for the Contact of A Rotary Burnishing Element with the Rough Surface of A Part, Providing A High-Quality Product", Journal of Mechanical Technology, 19, pp. 319-356, (1989).

[2] Loh, N. H., Tam, S. C. and Miyazawa, S., " A Study of the Effects of BallBurnishing Parameters on Surface Roughness Using Factorial Design", Journal of Mechanical Working Technology, 18, pp. 53-61, (1989). 
[3] Shneider, Yu. G., "Classification of Metal-Burnished Methods and Tools", Machines and Tooling Vol. XL, No. 1, p. 35, (1969).

[4] El-Axir, M. H., " An Investigation Into Roller Burnishing" International Journal of Machine tool \& Manufacturing 40, pp. 1603-1617, (2000).

[5] Loh, N. H., Tam, S. C. and Miyazawa S.," Statistical Analyses of the effects of ball Burnishing Parameters on Surface Hardness", Wear, 129, pp. 235, (1989).

[6] Yashcheritsyn, I., Pyatosin E.I. and Votchuga, V. V., " Hereditary Influence of pretreatment on Roller-Burnishing Surface wear Resistance" Soviet Journal of Friction and Wear, Vol. 8, No.2, pp. 87, (1987).

[7] Fattouh, M., M. H. El-Axir, Serage, S. M.," Investigation into the Burnishing of External Cylindrical surface of 70/30 Cu-Zn-Alloy", Wear. P. 127, (1988).

[8] Lee, S. S.G., Tam S.C. Loh N.H. and Miyazawa, S. "An Investigation into the Ball Burnishing of an AISI 1045 Free-Form Surface", Journal of Materials Processing Technology, 29, P. 203, (1992).

[9] Lee, S.S.G., Tam S.C. and . Loh, N. H," Ball Burnishing of 316L Stainless Steel", Journal of Materials Processing Technology, 37, P. 241, (1993).

[10] Fattouh, M., El-Khabeery, M. M.," Residual Stress Distribution in Burnishing Solution Treated and Aged 7075 Aluminum Alloy", Int. J. Mach. Tools Manufact., Vol. 29, No. 1, P. 153, (1989).

[11] Niberg, A. N. "Wear Resistance of Sideways Strengthened by Burnishing", Soviet Engineering Research, Vol. 7, No. 5 P. 67, (1987).

[12] Michael, P. C., Saka N., and Rabinowicz, E., " Burnishing and Adhesive wear of an Electrically Conductive Polyester-Carbon Film, Wear, 132, P. 265, (1989).

[13] Das, M. N. and Giri, N. G., " Design and Analysis of Experimentals", John Wiley \& Sons, New York, Second Edition, (1980). 


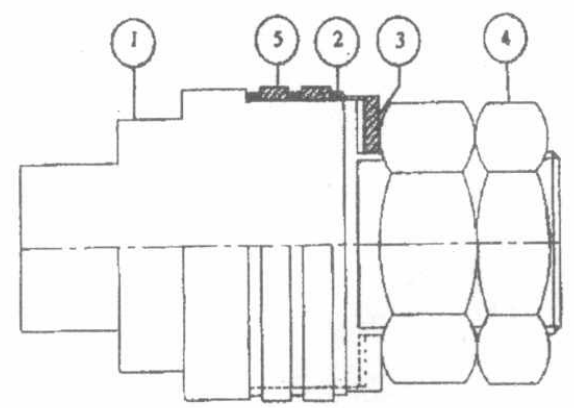

\begin{tabular}{|l|c|l|c|}
\hline 3 & Cover & & \\
\hline 2 & Washer & 5 & Workpiece \\
\hline 1 & Base & 4 & Nut \\
\hline Part No. & Part name & Part No. & Part name \\
\hline
\end{tabular}

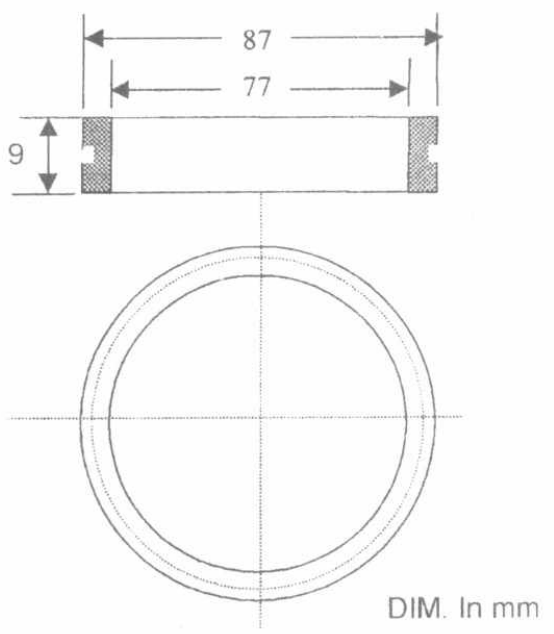

Fig. 2 Mandrel and workpiece assembly

Fig. 1 Workpiece geometry
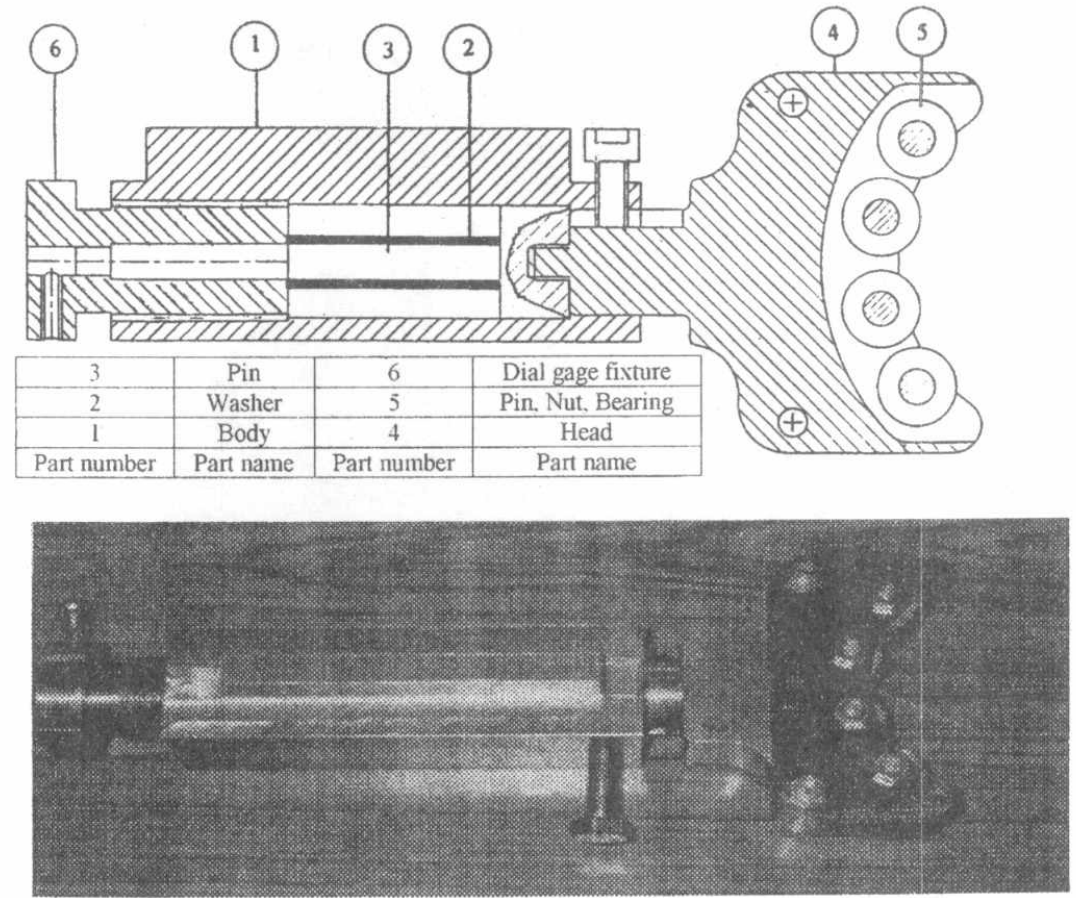

Fig. 3 Four Roller burnishing tool 


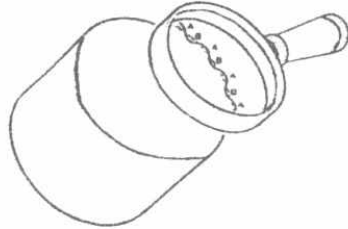

Fig. 4a Shaft diameter (enlarged view)

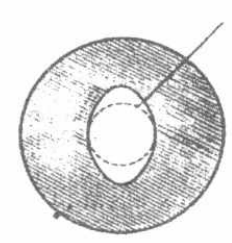

Fig. 4b Shaft ovalness

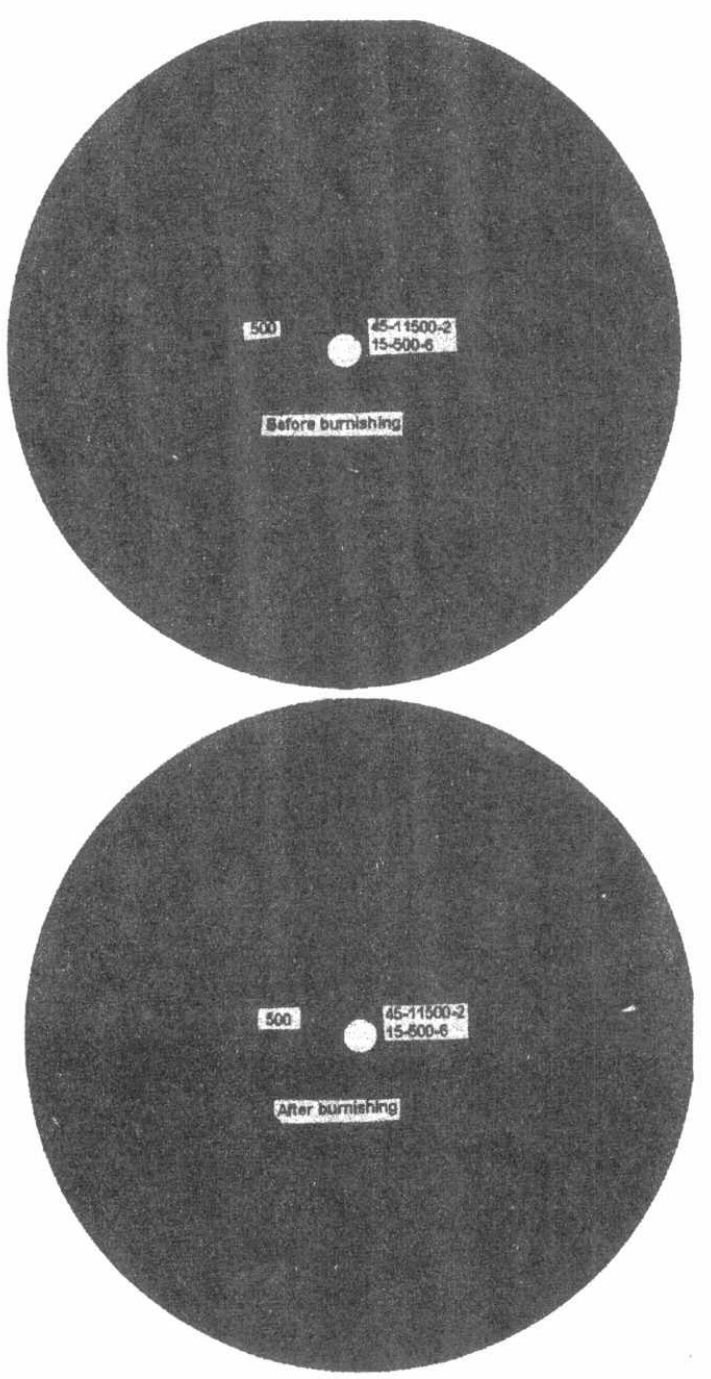

Fig. 5 Out - of - roundness before and after burnishing 


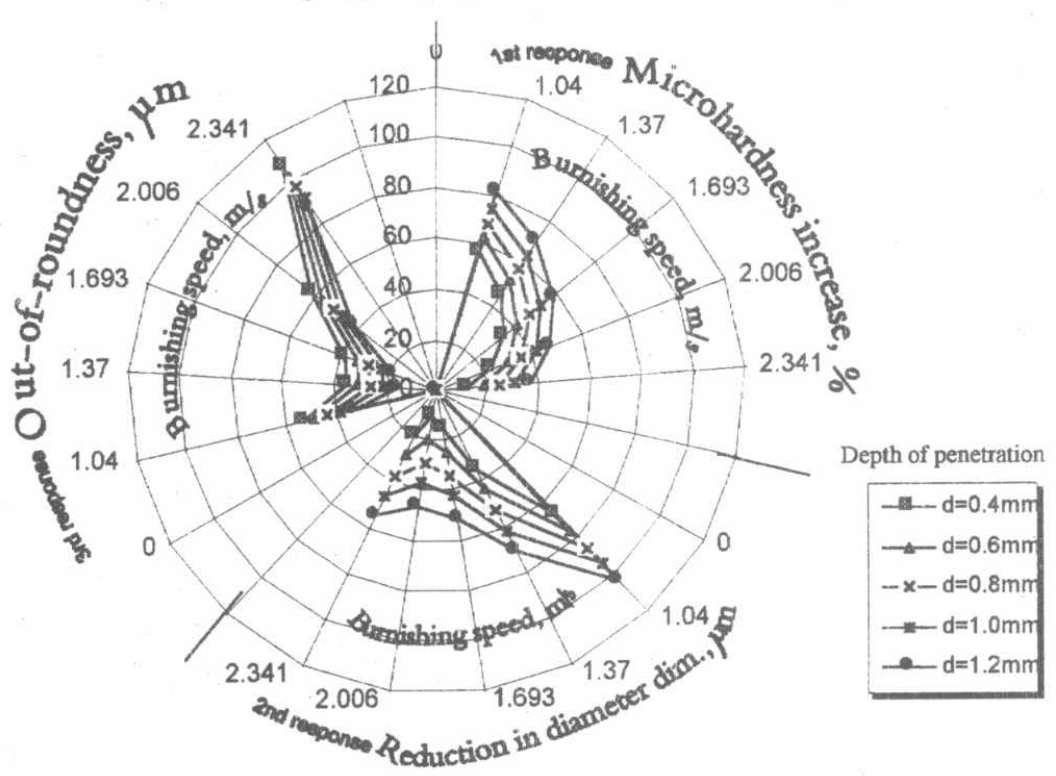

Fig. 6 Effect of burnishing speed on percentage of microhardness increase, reduction in diameter dimension and out-of-roundness at different depths of penetration

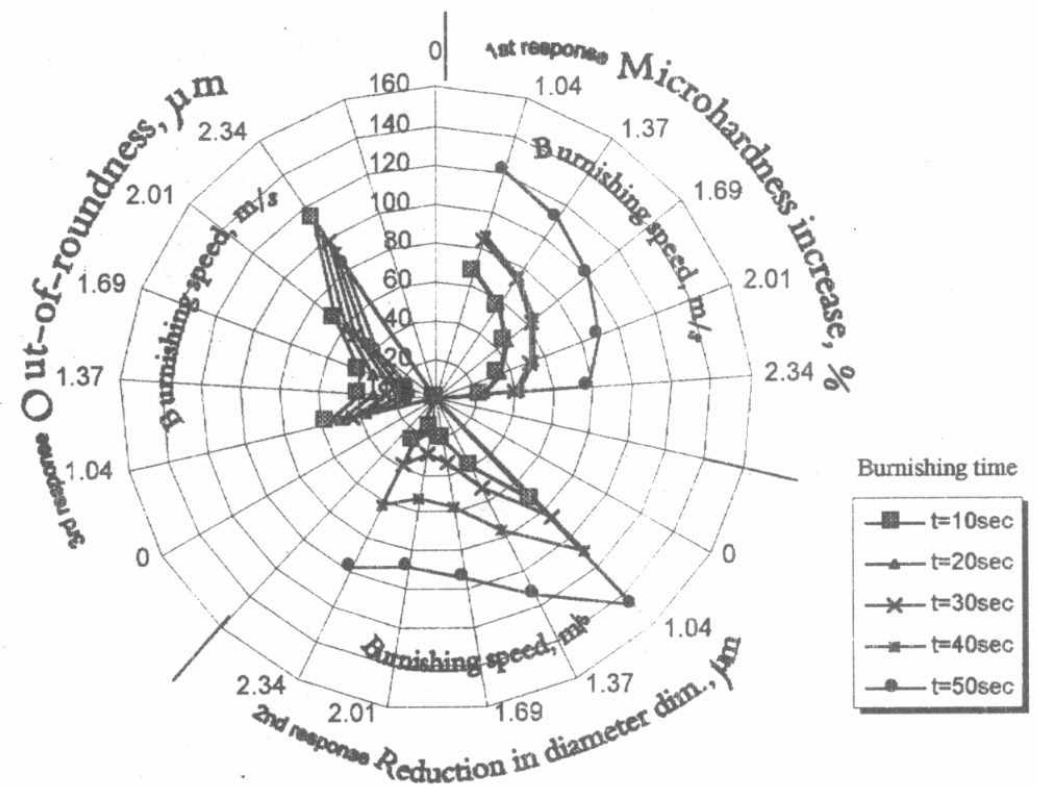

Fig. 7 Effect of burnishing speed and burnishing time on percentage of microhardness increase, reduction in diameter dimension and out-of-roundness 


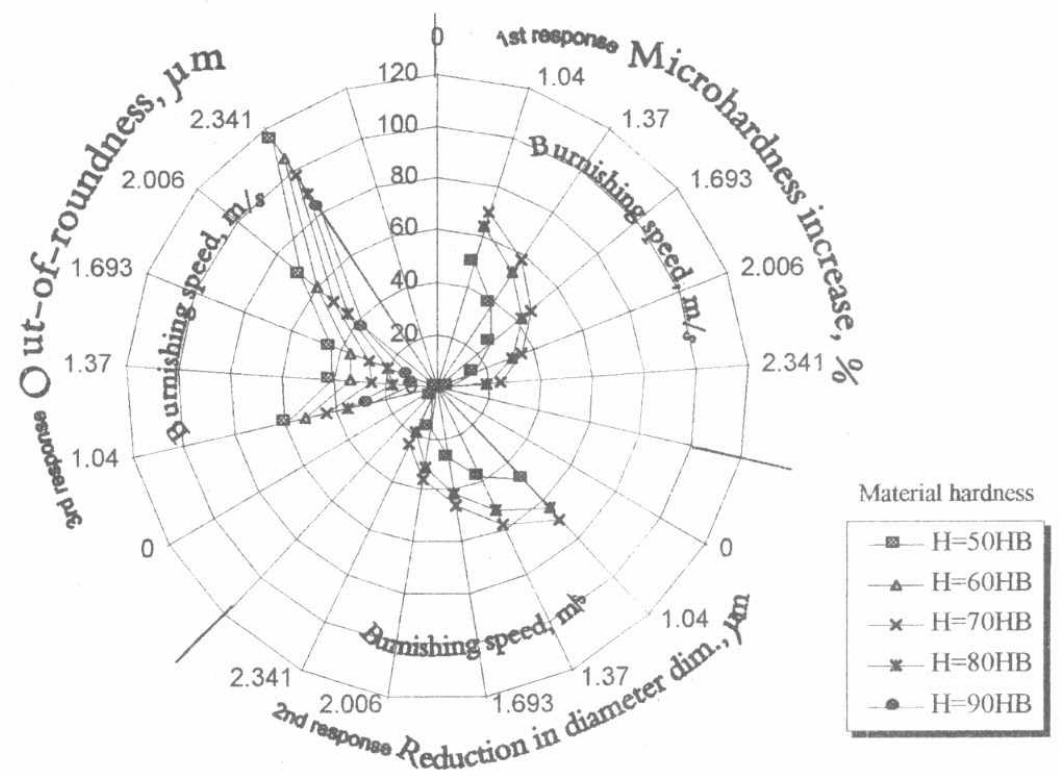

Fig. 8 Effect of burnishing speed on the percentage of microhardness increase, reduction in diameter dimension and out-of-roundness at different and material hardness

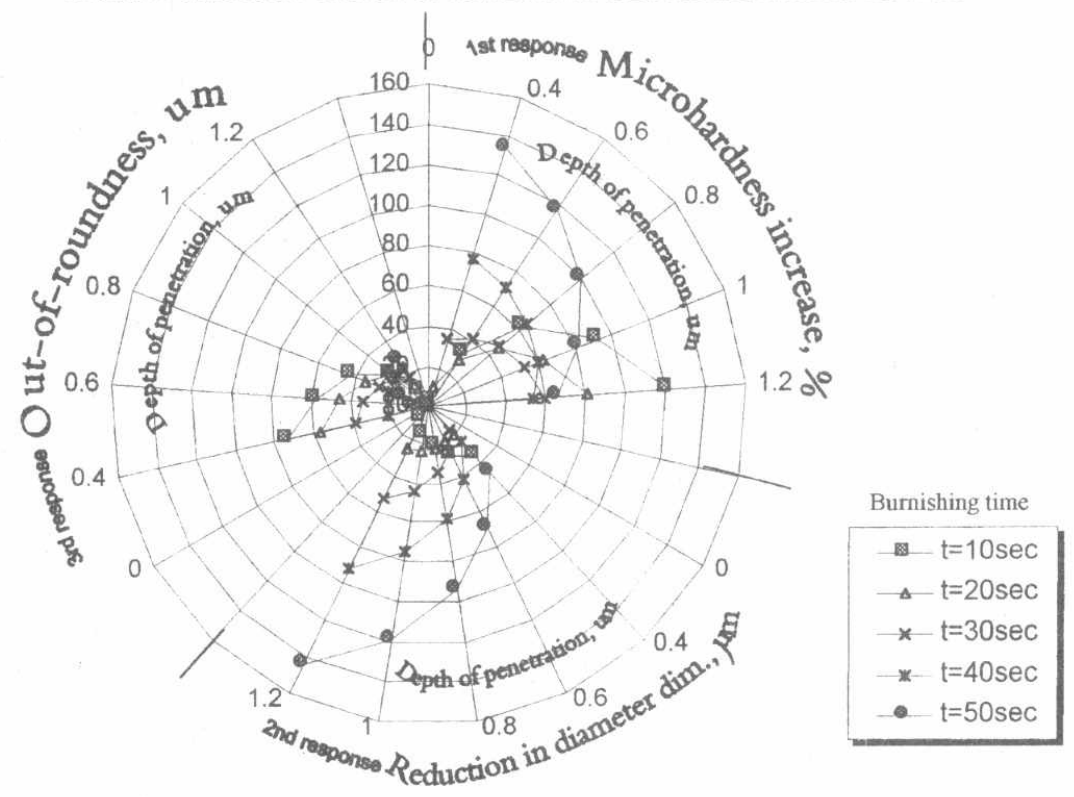

Fig. 9 Effect of depth of penetration on the percentage of microhardness increase, reduction in diameter dimension and out-of-roundness at different burnishing times 


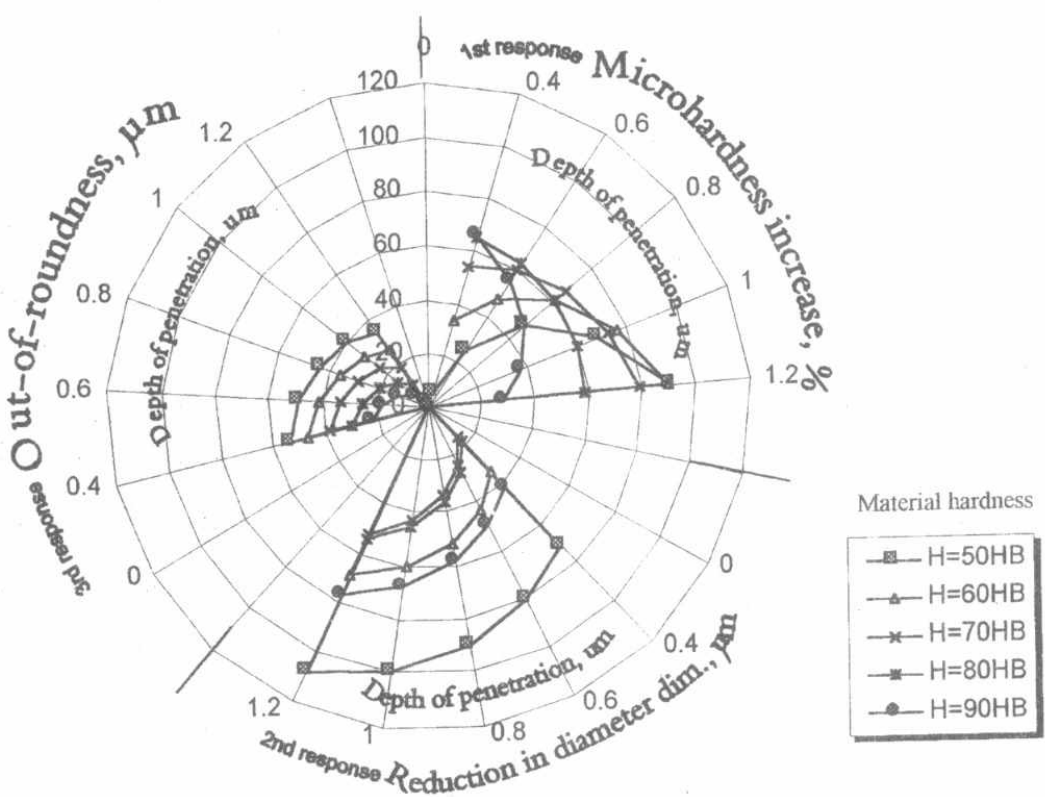

Fig. 10 Effect of depth of penetration on the percentage of microhardness increase, reduction in diameter dimension and out-of-roundness at different material hardness

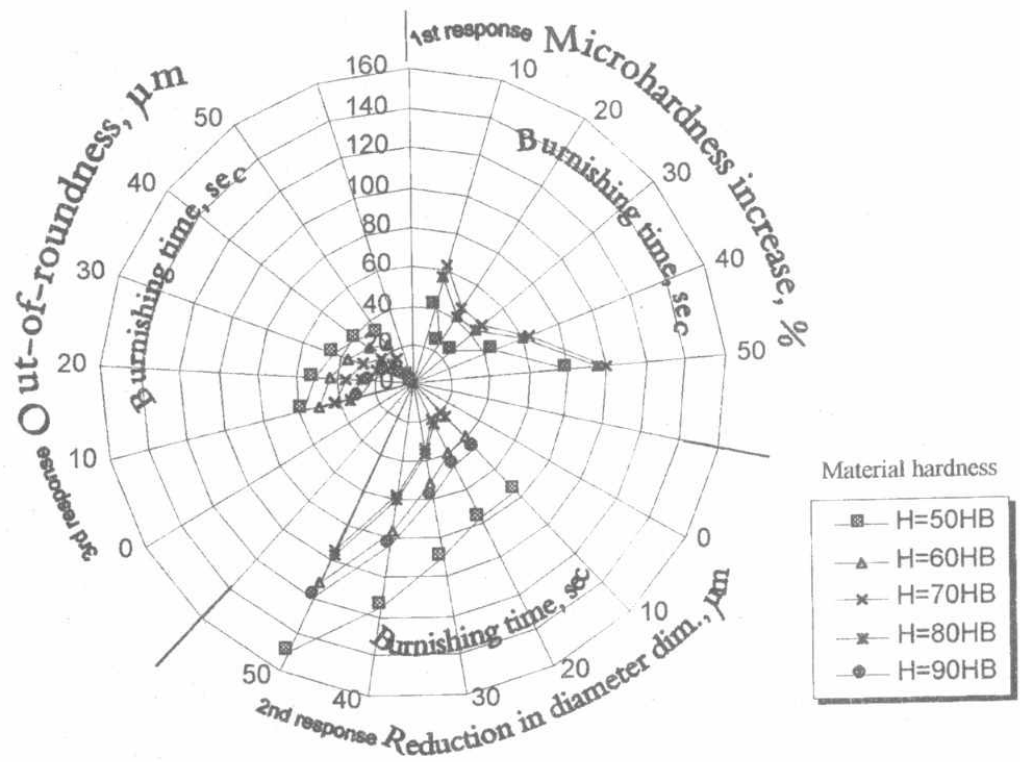

Fig. 11 Effect of burnishing time on the percentage of microhardness increase, reduction in diameter dimension and out-of-roundness at different material hardness 